Article

\title{
DC Voltage Adaptive Droop Control Strategy for a Hybrid Multi-Terminal HVDC System
}

\author{
Yingpei Liu *, La Zhang and Haiping Liang
}

School of Electrical and Electronic Engineering, North China Electric Power University, Baoding 071003, China; 2162213091@ncepu.edu.cn (L.Z.); lianghaiping@ncepu.edu.cn (H.L.)

* Correspondence: liuyingpei@ncepu.edu.cn; Tel.: +86-155-1120-0089

Received: 30 November 2018; Accepted: 22 January 2019; Published: 25 January 2019

\begin{abstract}
To solve the problems of DC voltage control and power allocation in the hybrid multi-terminal high voltage direct current system effectively, a DC voltage adaptive droop control strategy based on DC voltage-current characteristics is proposed. Based on adjustment of the droop coefficient of the converter station, the proposed control strategy introduces the influence factor of the droop coefficient, which considers the dynamic power margin of the converter station according to the direction of DC current variation in the converter station. When changes in the hybrid multi-terminal high voltage direct current system power flow occur, the droop coefficient of the converter station can be adjusted by the influence factor of the droop coefficient, so that the converter station can participate in power regulation according to its own power regulating ability. Consequently, the proposed control strategy can reasonably allocate the active power and minimize the deviation of the DC voltage. Besides, the stability analysis of the proposed control strategy is also carried out. Simulation results have verified the feasibility and effectiveness of the proposed control strategy.
\end{abstract}

Keywords: adaptive droop control; deviation of the DC voltage; hybrid multi-terminal high voltage direct current system; influence factor of the droop coefficient; power margin

\section{Introduction}

The line commutated converter based high voltage direct current (LCC-HVDC) system has been widely utilized in many areas due to high power capability, low losses, and economic advantages. However, LCC-HVDC has a strong dependence on the AC grid, thus, if the interferences occur in an AC grid, LCC-HVDC would be susceptible to commutation failures [1-3].

Nowadays, voltage source converter based high voltage direct current (VSC-HVDC) has been developing rapidly. It has many advantages, such as independent control of active power and reactive power, high switching frequency and low harmonics, and its ability to provide dynamic reactive power support for the AC grid. Due to its advantages, it is a potential solution to the new energy grid-connection. However, VSC-HVDC are worse than LCC-HVDC in both costs and losses [4].

The hybrid high voltage direct current (Hybrid-HVDC) system formed with VSC and LCC combines the advantages of LCC-HVDC and VSC-HVDC. This paper focuses on the Hybrid-HVDC system that adopts voltage source converter (VSC) on the rectifier side and line commutated converter (LCC) on the inverter side. Compared with LCC-HVDC, the Hybrid-HVDC system can provide reactive power support for the AC grid at the sending end. Compared with VSC-HVDC, the Hybrid-HVDC system has lower switching losses, more mature technology, and lower capital costs. With the increasing demand of new energy grid-connection, the hybrid multi-terminal HVDC (Hybrid-MTDC) system has become the inevitable development trend of the HVDC transmission system [5-8].

Hybrid-MTDC has more flexible operation modes than the two-terminal hybrid HVDC system, and the power coordination between converter stations is very important for the Hybrid-MTDC system. 
Therefore, it is necessary to study the coordinated control strategies of Hybrid-MTDC to improve the ability of power regulation [9]. At present, three basic methods that control the MTDC system, namely, master-slave control strategy, voltage margin control strategy, and DC voltage droop control strategy, have been proposed [10]. DC voltage droop control combined with fixed DC voltage control and fixed active power control can control DC voltage at the same time by multiple converter stations, and can distribute active power in proportion to the droop coefficient, which is widely used in the MTDC system [11].

In the last few years, scholars at home and abroad have studied the problems of droop control strategy, including overload of the converter station, DC voltage deviation, tedious setting of the droop coefficient, and the influence of the droop coefficient on the control performance. To maintain the power balance of the MTDC system, a control method, based on frequency-domain stability analysis, was presented by Prieto-Araujo, E. and Bianchi, F.D. to provide a selection standard for the droop coefficient. However, the selection method of the droop coefficient is based on an accurate DC network mathematical model, which is not suitable for the large-scale HVDC system [12]. In [13,14], the optimal solutions of DC voltage and active power instructions for each converter station were obtained at the upper controllers to improve the droop control performance. However, communications between converter stations and the upper controllers are needed. In consequence, the reliability of the MTDC system decreases. The core idea of droop control proposed in [15] is to divide converter stations into four converter station groups that are set at different voltage margins and dead zones to set the priority level for coordinated control. As a result, converter stations have good dynamic characteristics in the transient state. Aiming at the situations of DC voltage oscillations caused by AC side faults, Yan, F.Y. and Tang, G.F. improved the traditional DC voltage droop control strategy by introducing a common DC voltage reference value, which improved the stability of the system [16]. The droop control strategy proposed in reference [17] can reduce DC voltage deviation by introducing DC voltage feedback. However, both methods do not consider the power margin of the converter station, which can easily lead to the overload of the converter station. The authors in reference [18] proposed a power sharing adaptive droop control method, considers the dynamic power margin of the converter station to avoid overload. However, the influence of DC voltage deviation on the droop coefficient was not considered. In reference [19], a droop control strategy based on optimal power flow was provided, but the calculation time was a little longer. A droop control with DC voltage regulation and frequency support, which guarantees the rational distribution of active power and the effective regulation of DC voltage, was introduced in reference [20], but it requires high performance of the communication system. The authors in reference [21] introduced a droop control that adjusts the droop coefficient according to the power margin and DC voltage deviation. However, the calculation of the droop coefficient is too complicated, and the improper selection of the droop coefficient will lead to an increase of the DC voltage. In reference [22], a droop control strategy was proposed that introduced a power margin factor and voltage deviation factor to ensure good steady-state and dynamic performance of the converter station, but it did not consider the direction of DC voltage variation.

In this paper, a DC voltage adaptive droop control strategy based on DC voltage-current characteristics is studied. According to the direction of DC current variation in the converter station, the power margin of the converter station is obtained to introduce the influence factor of the droop coefficient. By introducing the influence factor of the droop coefficient, the proposed control strategy can adjust the droop coefficient in real time. Consequently, the control strategy allocates the power reasonably and minimizes the deviation of the DC voltage. Besides, the stability analysis of the proposed control strategy is also carried out. Finally, the feasibility and effectiveness of the proposed control strategy are verified through simulation analyses of a four-terminal hybrid HVDC system performed in PSCAD/EMTDC.

The rest of this paper is organized as follows. In Section 2, the Hybrid-MTDC system is outlined. The DC voltage adaptive droop control strategy is systematically derived in Section 3 . Section 4 validates the control performance of the DC voltage adaptive droop control strategy on PSCAD/EMTDC. Conclusions are drawn in Section 5. 


\section{Hybrid-MTDC System}

The topology of the parallel four-terminal hybrid HVDC system is shown in Figure 1. VSC1 and VSC2 are rectifier stations, while LCC 3 and LCC4 are inverter stations. $T_{i}$ is the converter transformer of the $i^{\text {th }}(i=1,2,3,4)$ converter station. $P_{i}$ and $Q_{i}$ are the active power and reactive power of the $i^{\text {th }}$ converter station, respectively.

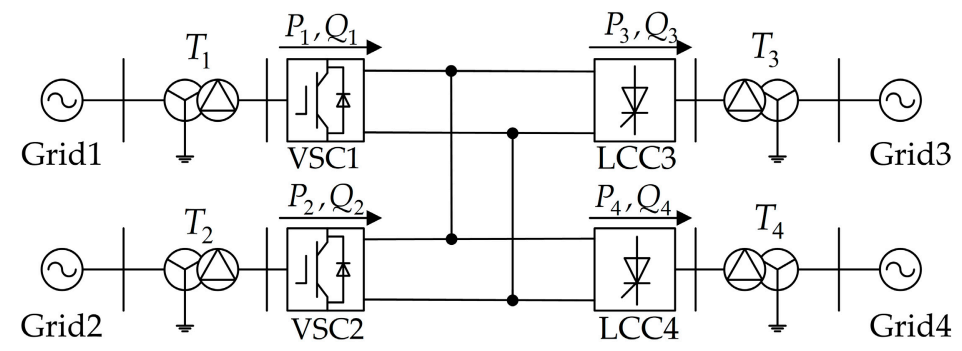

Figure 1. The topology of the parallel four-terminal hybrid HVDC system.

The bipolar Hybrid-HVDC system has a higher voltage level and transmission capacity, which is suitable for the occasion with high reliability. The structure of the bipolar VSC converter station is shown in Figure 2, which consists of two sets of VSCs in series on the DC side. Furthermore, the neutral point between the two sets of VSCs is grounded.

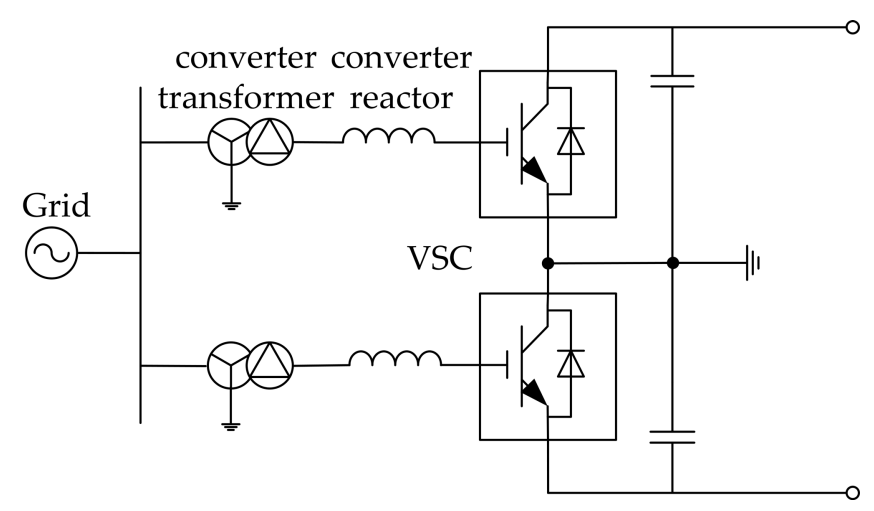

Figure 2. Structure of the bipolar voltage source converter station.

The structure of VSC is shown in Figure 3 , in which, $u_{s k}, i_{s k}$, and $u_{k}(k=a, b, c)$ are the AC grid voltage, the AC grid current, and the fundamental component of the converter's output voltage, respectively. $R$ and $L$ are the equivalent resistance and equivalent inductance between the AC grid and the converter, respectively.

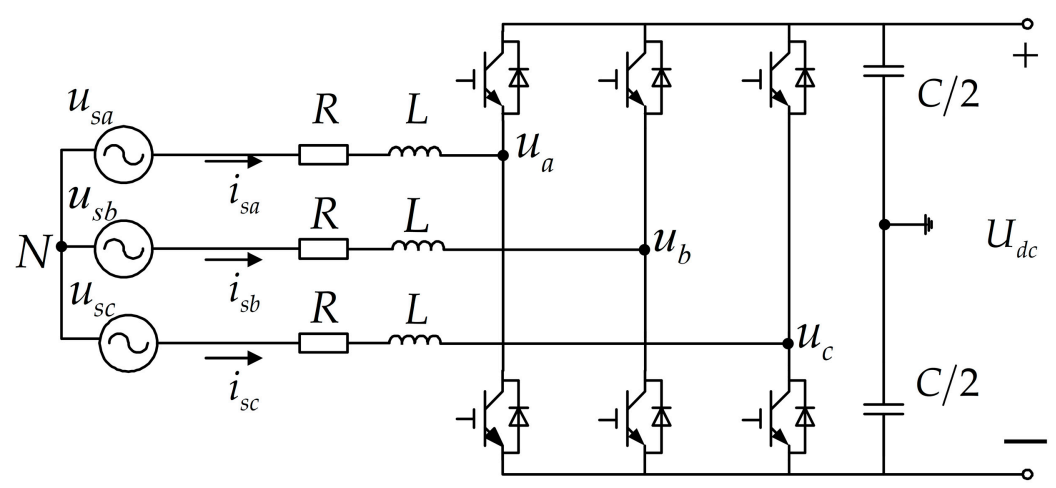

Figure 3. Structure of VSC. 
Assuming the AC grid has three-phase symmetry, the mathematical model of VSC in the $a b c$ reference frame is [23]:

$$
\left\{\begin{array}{l}
L \frac{d i_{s a}}{d t}=u_{s a}-R i_{s a}-u_{a} \\
L \frac{i_{s b}}{d t}=u_{s b}-R i_{s b}-u_{b} \\
L \frac{d i_{s c}}{d t}=u_{s c}-R i_{s c}-u_{c}
\end{array}\right.
$$

By using Park transformation, the mathematical model of VSC in the $d q$ reference frame is:

$$
\left\{\begin{array}{l}
L \frac{d i_{s d}}{d t}=-R i_{s d}+\omega L i_{s q}+u_{s d}-u_{d} \\
L \frac{d i_{s q}}{d t}=-R i_{s q}-\omega L i_{s d}+u_{s q}-u_{q}
\end{array}\right.
$$

where $u_{s d}$ and $u_{s q}$ are components of the AC grid voltage in the $d q$ axis, respectively; $u_{d}$ and $u_{q}$ are components of the fundamental component of the converter's output voltage in the $d q$ axis, respectively; $i_{s d}$ and $i_{s q}$ are the components of the AC grid current in the $d q$ axis, respectively; and $\omega$ is the synchronous rotating angular velocity of the AC grid voltage vector.

The structure of the LCC converter station, which mainly consists of 12 pulse converters, converter transformer, AC filter, and smoothing reactor, is shown in Figure 4.

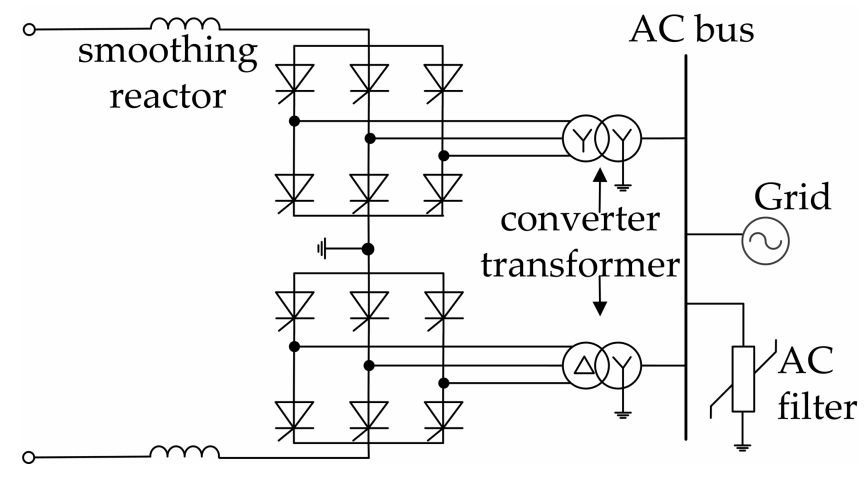

Figure 4. Structure of the line commutated converter station.

As the inverter station, the mathematical model of LCC is:

$$
U_{d c}=\frac{3 \sqrt{2}}{\pi} U_{2 L} \cos \beta+\frac{3}{\pi} X_{c} I_{d c}
$$

where $U_{d c}$ and $I_{d c}$ are the DC voltage and DC current of the converter station, respectively; $U_{2 L}$ is the effective value of line voltage at the transformer secondary-side; $\beta$ is the advance firing angle; and $X_{c}$ is the equivalent commutation reactance.

For the hybrid-MTDC system, the VSC converter stations being utilized for the new energy grid-connection adopt the constant active power control strategy, and the LCC converter stations connecting the active network apply DC voltage droop control strategy. Then, the operation characteristics of the four-terminal hybrid HVDC system are shown in Figure 5. 


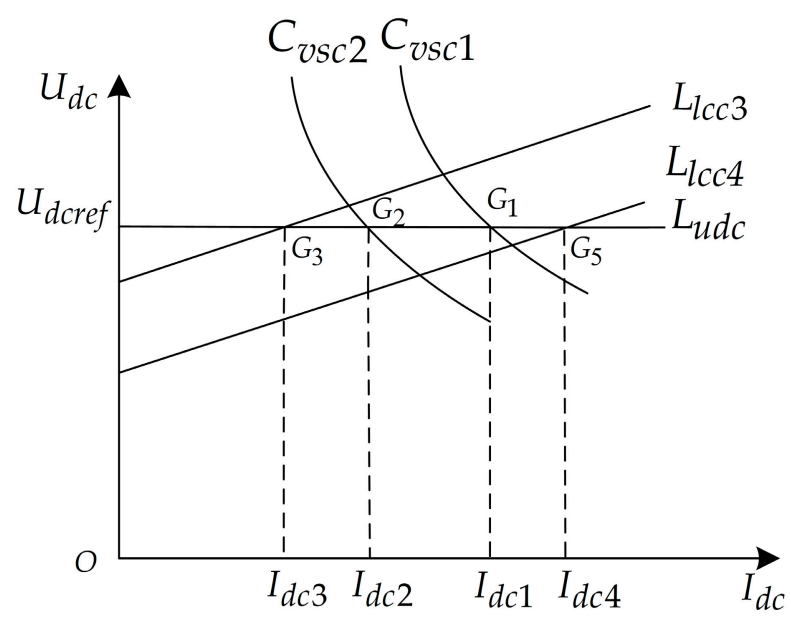

Figure 5. The operational characteristics of the four-terminal hybrid HVDC system.

$L_{l c c 3}$ and $L_{l c c 4}$ represent the droop characteristics of the LCC converter stations, and $C_{v s c 1}$ and $C_{v s c 2}$ represent the characteristics of the VSC converter stations. For the sake of analysis, the losses of the Hybrid-MTDC system are neglected so that all converter stations have the same DC voltage level, as shown by $L_{u d c}$. Then, the intersection point, $G_{i}$, between $L_{u d c}$ and the characteristic curve of the $i^{\text {th }}$ converter station is the stable operating point of the $i^{\text {th }}$ converter station. To maintain power balance, DC currents satisfy $I_{d c 1}+I_{d c 2}=I_{d c 3}+I_{d c 4}$.

\section{DC Voltage Adaptive Droop Control}

The traditional DC voltage droop control characteristics and controller structure are shown in Figures 6 and 7, respectively. In Figures 6 and 7, $U_{d c r e f}$ and $I_{d c r e f}$ are the DC voltage and DC current reference values of the converter station, respectively, $U_{d c \max }$ and $I_{d c m a x}$ are the upper limit of the DC voltage and DC current, respectively, and $K$ is the droop coefficient.

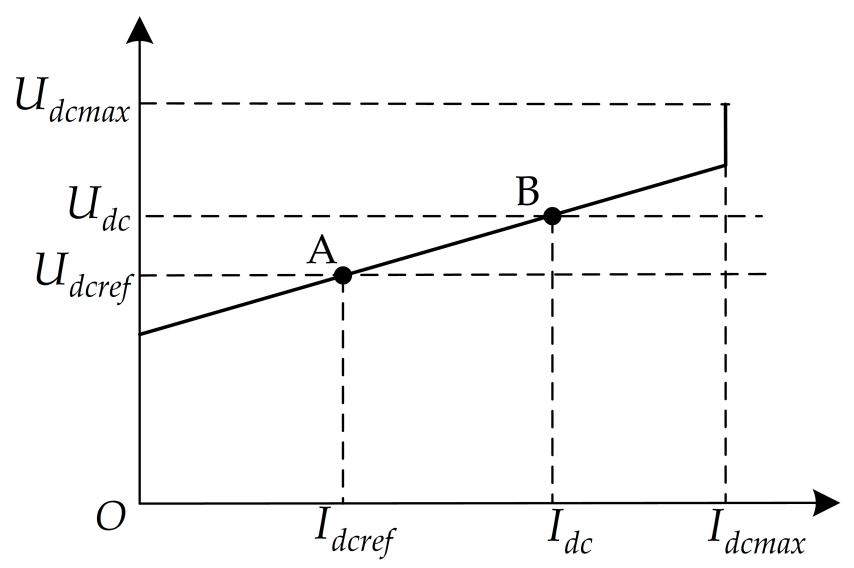

Figure 6. Characteristics of traditional DC voltage droop control.

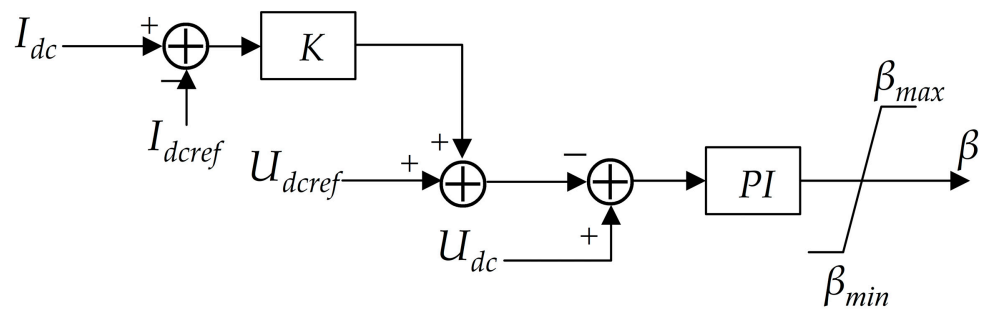

Figure 7. Traditional DC voltage droop controller. 
As can be observed from Figure 7, the relationship between the DC voltage and DC current is:

$$
U_{d c}-U_{d c r e f}=K\left(I_{d c}-I_{d c r e f}\right)
$$

As shown in Figure 6, when power flow changes in the Hybrid-MTDC system occur, the stable operating point of the converter station changes from $A$ to $B$, then the DC voltage deviation is:

$$
\Delta U_{d c}=U_{d c}-U_{d c r e f}=K\left(I_{d c}-I_{d c r e f}\right)
$$

In addition, the unbalanced power shared by the converter station is:

$$
\Delta P=U_{d c} I_{d c}-U_{d c r e f} I_{d c r e f}=U_{d c r e f}\left(I_{d c}-I_{d c r e f}\right)+\Delta U_{d c} I_{d c}
$$

In terms of the traditional DC voltage droop control strategy, the traditional droop coefficient, $K$, is described as follows:

$$
K=\frac{U_{d c \max }-U_{d c r e f}}{I_{d c m a x}}
$$

where $U_{d c m a x}-U_{d c r e f}$ is the upper limit of the DC voltage deviation, which generally takes $5 \%$ of $U_{d c r e f}$.

According to Equations (5) and (7), Equation (8) can be obtained as follows:

$$
\frac{\Delta U_{d c} I_{d c}}{U_{d c r e f}\left(I_{d c}-I_{d c r e f}\right)} \leq 5 \%
$$

That is to say, $\Delta U_{d c} I_{d c}$ is so small that it can be ignored compared with $U_{d c r e f}\left(I_{d c}-I_{d c r e f}\right)$. Therefore, the unbalanced power shared by the converter station can be expressed as:

$$
\Delta P=U_{d c r e f}\left(I_{d c}-I_{d c r e f}\right)=\frac{\Delta U_{d c} U_{d c r e f}}{K}
$$

As can be observed in Equations (5) and (9), the traditional droop coefficient, $K$, affects the control of the DC voltage and allocation of unbalanced power. The larger the $K$ is, the less the unbalanced power allocated to the converter station is.

The traditional droop coefficient, $K$, is fixed at a constant level. Without considering the power margin of the converter station, it is easy to cause an overload of the converter station and massive DC voltage deviation.

To solve the problems of the traditional DC voltage droop control strategy, this paper introduces the influence factor of the droop coefficient, which is defined as:

$$
\alpha= \begin{cases}\frac{U_{d c r e f} I_{d c}}{P_{\max }} & I_{d c}>I_{d c r e f} \\ \frac{\left(P_{\max }-U_{d c r e f} I_{d c}\right)}{P_{\max }} & I_{d c}<I_{d c r e f}\end{cases}
$$

where $P_{\max }$ is the rated active capacity of the converter station.

Without a loss of generality, there is:

$$
0<U_{d c r e f} I_{d c}<U_{d c \max } I_{d c \max }=P_{\max }
$$

Equations (10) and (11) show $0<\alpha<1$.

In terms of the DC voltage adaptive droop control strategy, the adaptive droop coefficient is defined as:

$$
K^{*}=K^{\alpha}-1 \quad(K>1)
$$

The relationship between the adaptive droop coefficient and the DC current is shown in Figure 8. 


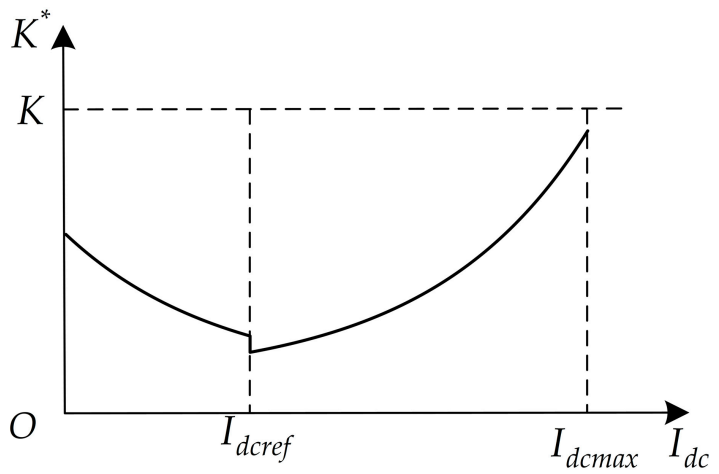

Figure 8. The relationship between the adaptive droop coefficient and the DC current.

In terms of the Hybrid-MTDC system, $P$ is the actual power of the converter station. In the initial state, the DC voltage and DC current of the converter station are stable at the reference value, namely, $U_{d c r e f}$ and $I_{d c r e f}$. When the DC current of the converter station increases, the DC current is smaller, and the power margin of the converter station is larger. When the DC current of the converter station decreases, the DC current is larger, and the power margin of the converter station is larger. According to Figure 8, the converter station with a larger power margin has a smaller adaptive droop coefficient, $K^{*}$.

Take the four-terminal hybrid HVDC system shown in Figure 1 as an example, the adjustment curve of the adaptive droop coefficient is shown in Figure 9. In the initial state, the DC current of the LCC3 converter station is smaller than that of the LCC4 converter station. When the DC current of the converter station increases, the LCC 3 converter station with a larger power margin automatically reduces the droop coefficient, which is smaller than that of the LCC4 converter station. Consequently, the unbalanced power allocated to the LCC3 converter station is relatively greater. Similarly, when the DC current of the converter station decreases, the LCC4 converter station with a larger power margin assumes more unbalanced power. As a result, the capacity of active power allocation of the converter station with the DC voltage adaptive droop control strategy is improved.

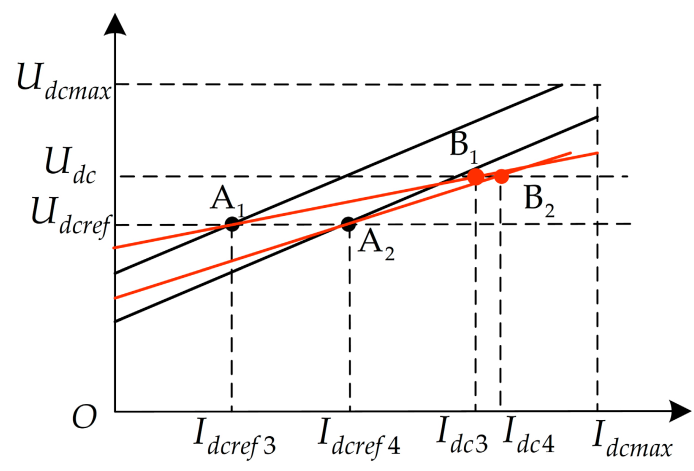

(a)

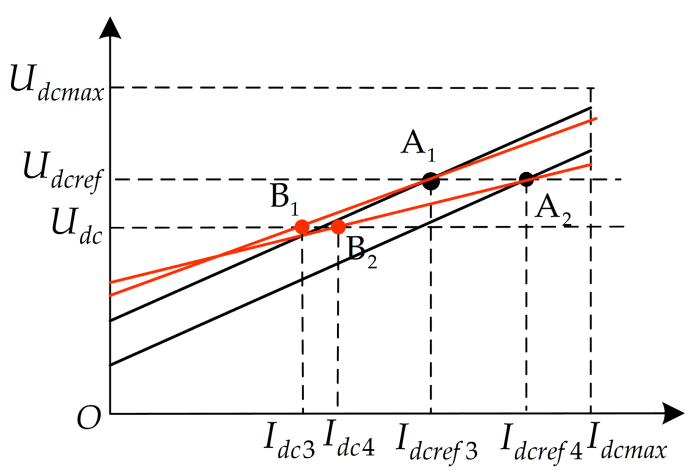

(b)

Figure 9. The adjustment curve of the adaptive droop coefficient: (a) The DC current increases; (b) the DC current decreases.

Substituting (12) into (5), the DC voltage deviation of the DC voltage adaptive droop control strategy is:

$$
\Delta U_{d c 1}=U_{d c}-U_{d c r e f}=\left(K^{\alpha}-1\right)\left(I_{d c}-I_{d c r e f}\right)
$$

Compared with the DC voltage deviation of traditional droop control, Equation (14) can be formulated as follows:

$$
\Delta U_{d c 1}-\Delta U_{d c}=\left(K^{\alpha}-1-K\right)\left(I_{d c}-I_{d c r e f}\right)
$$


Based on $K^{\alpha}-1-K<0$, Equation (15) can be obtained as follows:

$$
\left|\Delta U_{d c 1}\right|<\left|\Delta U_{d c}\right|
$$

According to Equation (15), compared with the traditional DC voltage droop control, the DC voltage adaptive droop control minimizes DC voltage deviation.

When power flow changes in the Hybrid-MTDC system occur, the DC voltage adaptive droop control strategy can maintain the stability of the system. To verify that the system can run stably in the new state, it is necessary to establish the transfer function of the LCC employing adaptive droop control. The steady-state DC equivalent circuit of the four-terminal hybrid HVDC system is shown in Figure 10.

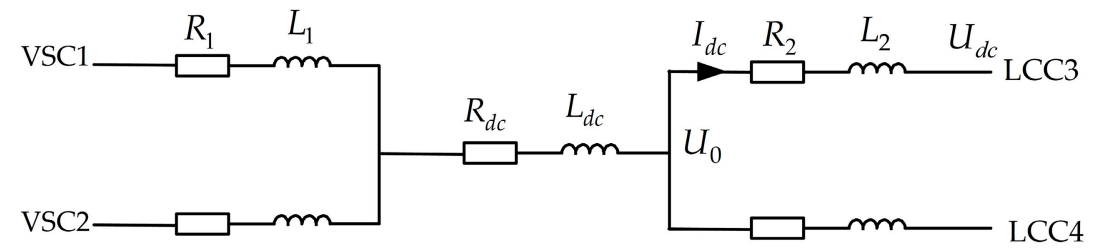

Figure 10. Steady-state DC equivalent circuit of the four-terminal hybrid HVDC system.

For the Hybrid-MTDC system, the relationship between the DC voltage and DC current of the converter station is:

$$
I_{d c}=\frac{U_{0}-U_{d c}}{R_{2}+s L_{2}}
$$

where $U_{0}$ is the DC voltage of the DC bus on the inverter side; $R_{2}$ and $L_{2}$ are the resistance and inductance between the converter station and the DC bus, respectively.

Substituting (16), Equation (3) can be rewritten as:

$$
U_{d c}=\frac{3 \sqrt{2}}{\pi} U_{2 L} \cos \beta+\frac{3}{\pi} X_{c} \frac{U_{0}-U_{d c}}{R_{2}+s L_{2}}
$$

Assuming that the DC current is a constant, the differential of (3) is:

$$
\frac{d}{d t} \Delta U_{d c}=-\frac{3 \sqrt{2}}{\pi} U_{2 L} \sin \beta \frac{d}{d t} \beta
$$

Therefore, the proportional integration (PI) control unit is:

$$
\beta=K_{p}\left(\frac{1}{\tau_{i} s}+1\right) \Delta U_{d c}
$$

where $K_{p}$ and $\tau_{i}$ are the proportional gain and time constant of the PI control unit, respectively.

From (13), (17), and (19), the transfer function block diagram of the LCC employing adaptive droop control can be obtained, as shown in Figure 11.

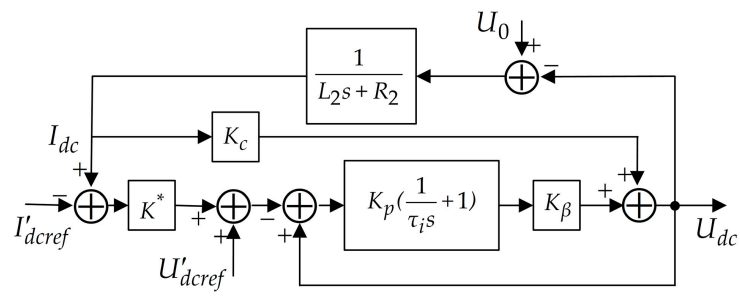

Figure 11. Transfer function block diagram of LCC employing adaptive droop control. 
Where $U^{\prime}{ }_{\text {ccref }}$ and $I^{\prime}{ }_{\text {dcref }}$ are the DC voltage and DC current of the converter station in the new state; $K_{c}=3 X_{c} / \pi ; K_{\beta}=3 \sqrt{2} U_{2 L} / \pi$.

Based on Figure 11, Equation (20) can be obtained as follows:

$$
\left\{\begin{array}{l}
G_{1}(s)=K_{\beta} K_{p}\left(1 / \tau_{i}+1\right) \\
G_{2}(s)=1 / L_{2} s+R_{2} \\
G(s)=1+K_{c} G_{2}(s)-G_{1}(s)-K^{*} G_{1}(s) G_{2}(s)
\end{array}\right.
$$

Therefore, the transfer function of the LCC employing adaptive droop control is:

$$
U_{d c}=\frac{\left(K_{c} G_{2}(s)-K_{c} G_{1}(s) G_{2}(s)+K^{*} G_{1}(s) G_{2}(s)\right) U_{0}}{G(s)}-\frac{G_{1}(s)\left(U_{d c r e f}^{\prime}-K^{*} I_{d c r e f}^{\prime}\right)}{G(s)}
$$

Taking the droop coefficient, $K^{*}$, as a variable, the root locus of the transfer function is drawn when the droop coefficient, $K^{*}$, increases from 0 , as shown in Figure 12. It can be observed from Figure 12 that the eigenvalues of the transfer function of the LCC converter station are negative when the droop coefficient, $K^{*}$, increases. Hence, the system can run stably in the new state. Because the eigenvalues have no imaginary part, the system is over-damped, and the unit step response is a non-periodic process. With the movement of the main pole, the dynamic performance of the system will be affected, that is, the response speed of the system slows down slightly with the increase of the droop coefficient, $K^{*}$.

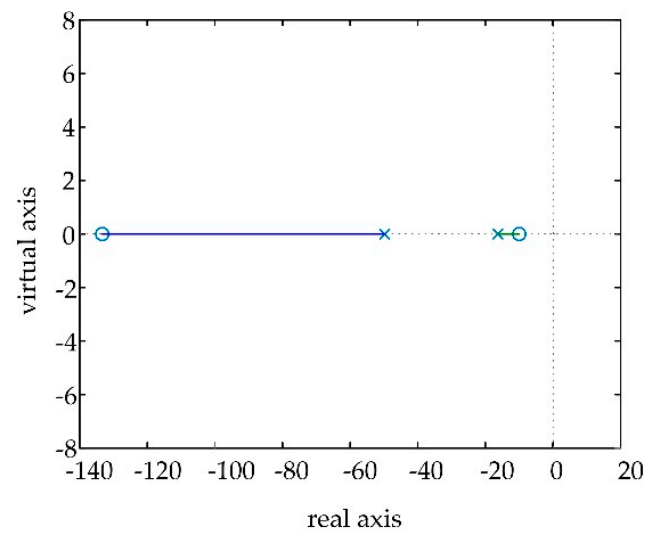

Figure 12. Root locus of the adaptive droop control converter station.

\section{Simulation and Discussion}

To verify the feasibility and effectiveness of the proposed control strategy, the four-terminal hybrid HVDC system shown in Figure 1 is built in PSCAD/EMTDC. VSC1 and VSC2 adopt the constant active power control; LCC3 and LCC4 apply DC voltage droop control. The simulations are carried out under various operating conditions, including steady-state and transient operating conditions. Parameters of the simulation system are shown in Table 1.

Table 1. Parameters of the simulation system.

\begin{tabular}{cc}
\hline Parameter & Value \\
\hline DC voltage reference value $U_{d c r e f} / \mathrm{kV}$ & 400 \\
Rated active capacity of VSC1 /MW & 500 \\
Rated active capacity of VSC2 /MW & 500 \\
Rated active capacity of LCC1/MW & 500 \\
Rated active capacity of LCC $/ \mathrm{MW}$ & 500 \\
DC current upper limit of LCC $/ \mathrm{kA}$ & 1.19 \\
DC side capacitance of VSC C $/ \mu \mathrm{F}$ & 5000 \\
LCC converter transformer ratio/ $/ \mathrm{kV} / \mathrm{kV})$ & $300 / 200$ \\
The traditional droop coefficient $K$ & 16.8 \\
\hline
\end{tabular}




\subsection{Steady-State Simulation Analysis}

\subsubsection{Increase of Active Power}

In this part, the four-terminal hybrid HVDC system is simulated when active power increases. In the initial state, the active power instruction values of VSC1 and VSC2 are $250 \mathrm{MW}$ and $400 \mathrm{MW}$, respectively; the DC current reference values of LCC3 and LCC4 are $0.52 \mathrm{kA}$ and $1.0 \mathrm{kA}$, respectively. At $6 \mathrm{~s}$, the active power instruction value of VSC1 rushes to $425 \mathrm{MW}$. The simulation results under the traditional DC voltage droop control and DC voltage adaptive droop control are shown in Figure 13.

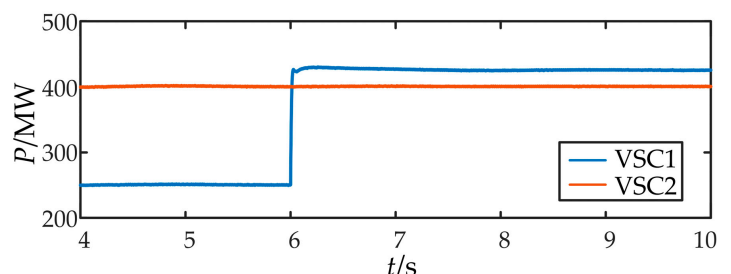

(a)

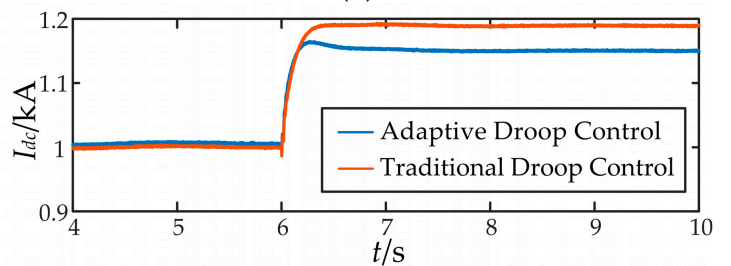

(c)

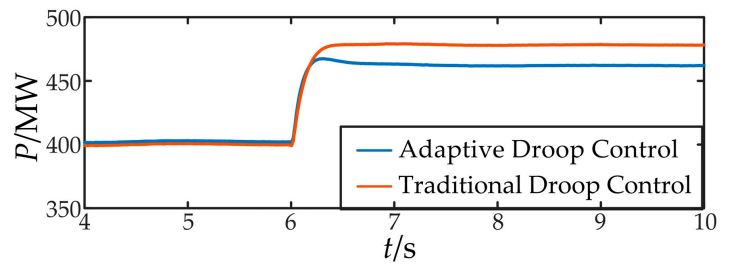

(e)

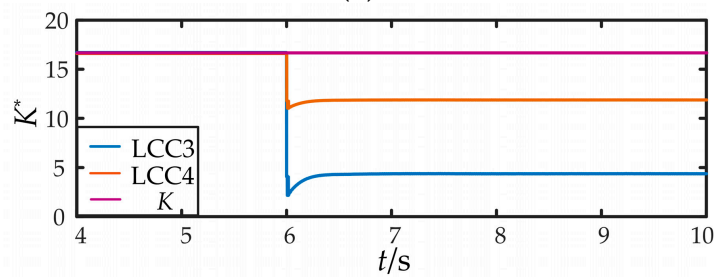

(g)

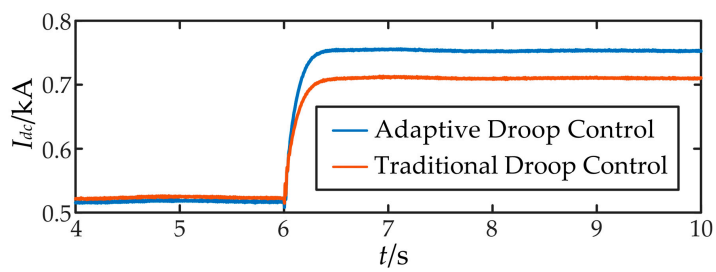

(b)

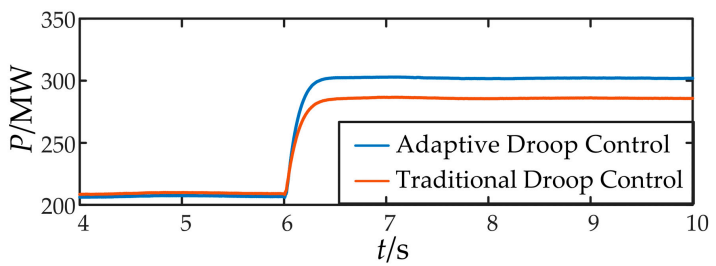

(d)

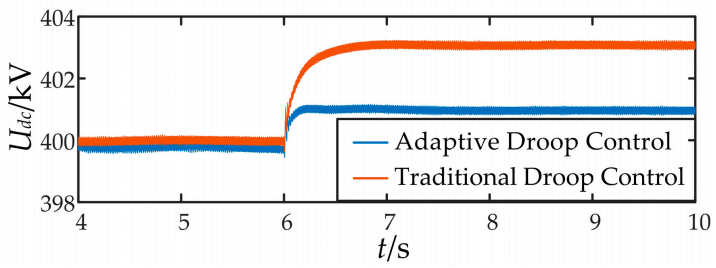

(f)

Figure 13. Simulation waveforms of an increase of active power: (a) Active power of VSC1 and VSC2; (b) DC current of LCC3; (c) DC current of LCC4; (d) active power of LCC3; (e) active power of LCC4; (f) DC voltage; (g) adaptive droop coefficient of LCC converter stations.

The simulation results show that the DC voltage increases when the active power of VSC1 increases at $6 \mathrm{~s}$. For the traditional DC voltage droop control strategy, the DC voltage increases from $400 \mathrm{kV}$ to $403 \mathrm{kV}$. At the same time, the DC current of two LCC converter stations both increase $0.19 \mathrm{kA}$. As a result, the DC current of LCC4 reaches its upper limit value of $1.19 \mathrm{kA}$, which causes LCC4 to switch to the constant current control mode. However, by utilizing the DC voltage adaptive droop control strategy, the DC voltage increases from $400 \mathrm{kV}$ to $401 \mathrm{kV}$. Owing to a larger power margin, the droop coefficient of LCC3 is smaller than that of LCC4. As a result, the LCC3 shares more unbalanced power, and the DC current of LCC3 increases by $0.234 \mathrm{kA}$. Hence, it avoids the situation that the LCC4 converter station switches to the constant current control mode due to an overload. 
Based on the above analysis, for the DC voltage adaptive droop control strategy, the converter stations share the power based on power margins, which improves the power regulation ability of the converter station and prevents the converter stations from overloading. At the same time, the DC voltage deviation decreases. In addition, it can be observed that the Hybrid-MTDC system with DC voltage adaptive droop control has a faster response speed.

\subsubsection{Decrease of Active Power}

In this part, the four-terminal hybrid HVDC system is simulated when active power decreases. In the initial state, the active power instruction values of VSC1 and VSC2 are $250 \mathrm{MW}$ and $400 \mathrm{MW}$, respectively, and the DC current reference values of LCC3 and LCC4 are $0.52 \mathrm{kA}$ and $1.0 \mathrm{kA}$, respectively. At $6 \mathrm{~s}$, the active power instruction value of the VSC2 converter station rushes to $160 \mathrm{MW}$. The simulation results under traditional DC voltage droop control and DC voltage adaptive droop control are shown in Figure 14.

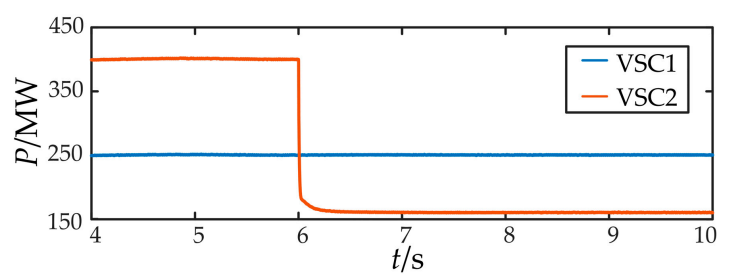

(a)

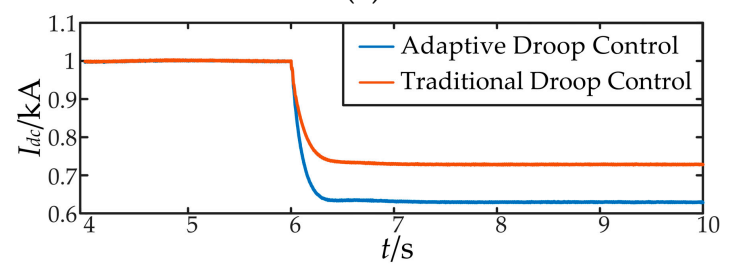

(c)

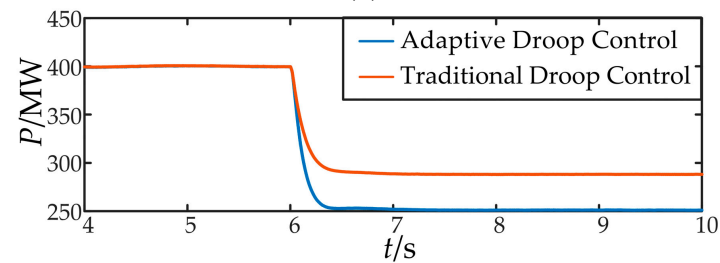

(e)

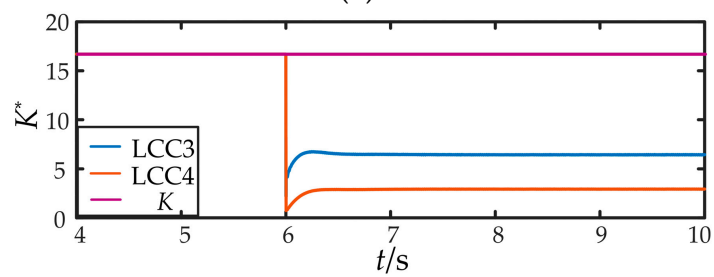

(g)

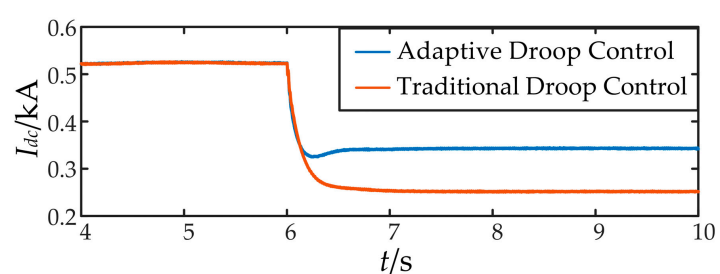

(b)

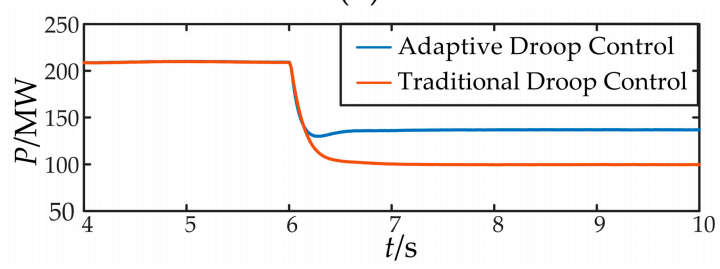

(d)

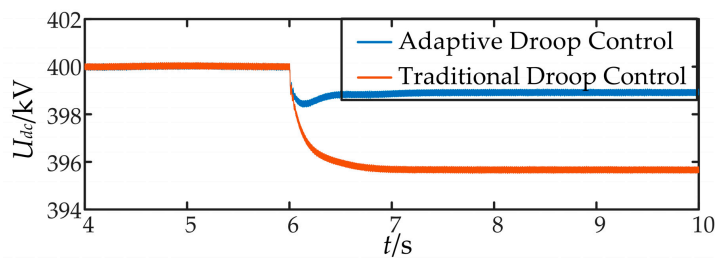

(f)

Figure 14. Simulation waveforms of a decrease of active power: (a) Active power of VSC1 and VSC2; (b) DC current of LCC3; (c) DC current of LCC4; (d) active power of LCC3; (e) active power of LCC4;

(f) DC voltage; (g) adaptive droop coefficient of LCC converter stations.

As shown in Figure 14, the DC voltage decreases when the active power of VSC2 decreases at $6 \mathrm{~s}$. For the traditional DC voltage droop control strategy, the DC voltage decreases from $400 \mathrm{kV}$ to $395.5 \mathrm{kV}$. At the same time, the DC current of two LCC converter stations decreases by $0.27 \mathrm{kA}$. For the $\mathrm{DC}$ voltage adaptive droop control strategy, the DC voltage decreases from $400 \mathrm{kV}$ to $399 \mathrm{kV}$. Owing to a larger power margin, the droop coefficient of LCC4 is smaller than that of LCC3. As a result, the DC 
current reduction amplitude of LCC4 is $0.37 \mathrm{kA}$, which is larger than that of LCC3. In other words, the unbalanced power is mainly shared by LCC4.

From the above analysis, it can be observed that the converter stations employing the DC voltage adaptive droop control strategy share the power based on power margins, which improves the power regulation ability of the converter station. At the same time, the DC voltage deviation decreases. In addition, it is shown that the Hybrid-MTDC system with the DC voltage adaptive droop control has a faster response speed.

\subsection{Transient Simulation Analysis}

\subsubsection{LCC3 Being Out of Operation}

To verify the reliability of the adaptive droop control strategy, N-1 operation simulation for the hybrid-MTDC system is carried out. In the initial state, the active power instruction values of VSC1 and VSC2 are $300 \mathrm{MW}$ and $200 \mathrm{MW}$, respectively, and the DC current reference values of LCC 3 and LCC 4 are $0.5 \mathrm{kA}$ and $0.69 \mathrm{kA}$, respectively. At $6 \mathrm{~s}, \mathrm{LCC} 3$ exits due to a failure. The simulation results under traditional DC voltage droop control and DC voltage adaptive droop control are shown in Figure 15.

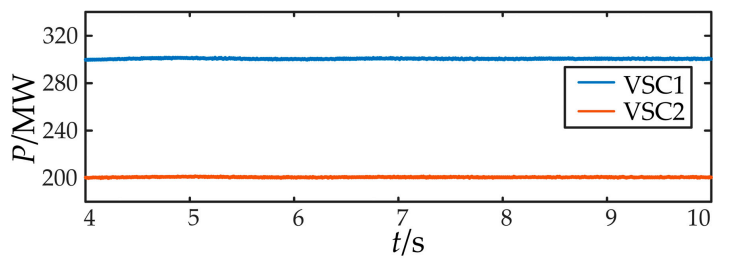

(a)

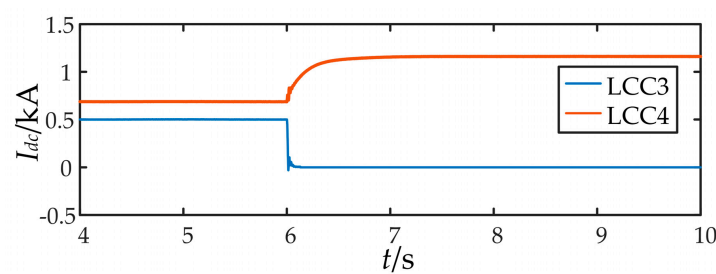

(c)

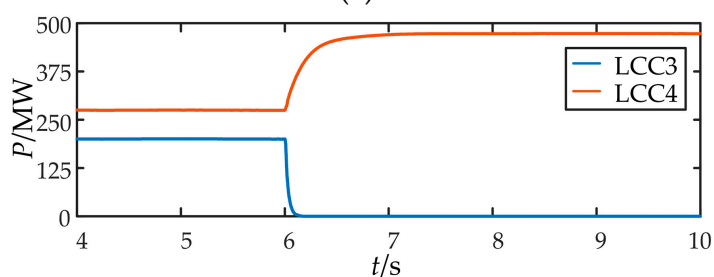

(e)

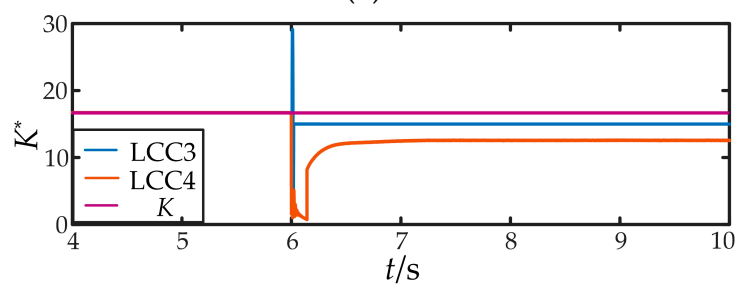

(g)

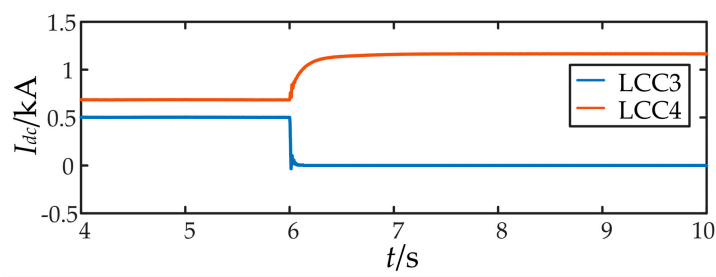

(b)

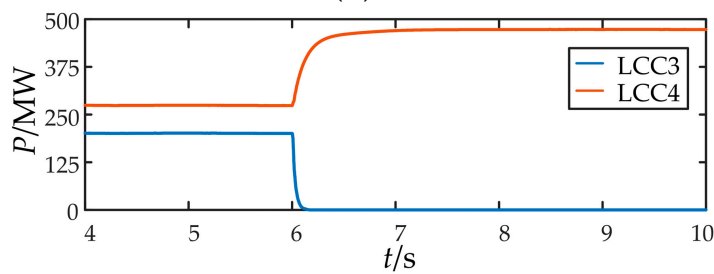

(d)

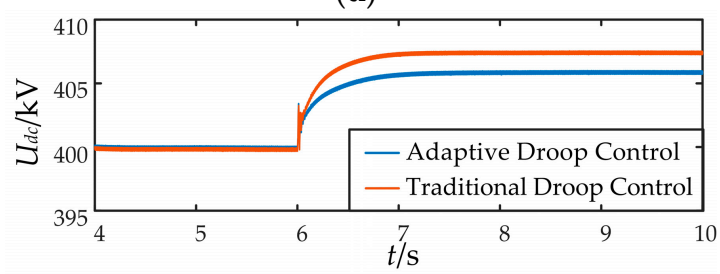

(f)

Figure 15. Simulation waveforms of LCC3 being out of operation: (a) Active power of VSC1 and VSC2; (b) DC current of LCC with adaptive droop control; (c) DC current of LCC with traditional droop control; (d) active power of LCC with adaptive droop control; (e) active power of LCC with traditional droop control; (f) DC voltage; (g) adaptive droop coefficient of LCC converter stations. 
The simulation results in Figure 15 show that when LCC 3 exits at 6 s, LCC 4 regulates the active power. Under two droop control strategies, the DC current and active power changes of LCC 3 and LCC4 are basically the same. For the traditional DC voltage droop control strategy, the DC voltage increases from $400 \mathrm{kV}$ to $407.5 \mathrm{kV}$. However, by using the DC voltage adaptive droop control strategy, the DC voltage increases from $400 \mathrm{kV}$ to $406 \mathrm{kV}$. That is to say, DC voltage adaptive droop control minimizes DC voltage deviation while maintaining the stability of the system.

\subsubsection{AC Grid Fault at the Receiving End}

In the initial state, the active power instruction values of VSC1 and VSC2 are $300 \mathrm{MW}$ and $200 \mathrm{MW}$, respectively, and the DC current reference values of LCC 3 and LCC4 are $0.5 \mathrm{kA}$ and $0.69 \mathrm{kA}$, respectively. At $6 \mathrm{~s}$, a three phase short circuit fault occurs in the AC grid on the LCC 3 side, and the fault lasts $500 \mathrm{~ms}$. The simulation results under traditional DC voltage droop control and DC voltage adaptive droop control are shown in Figure 16.

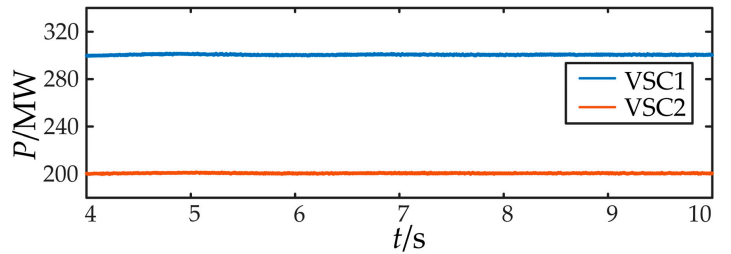

(a)

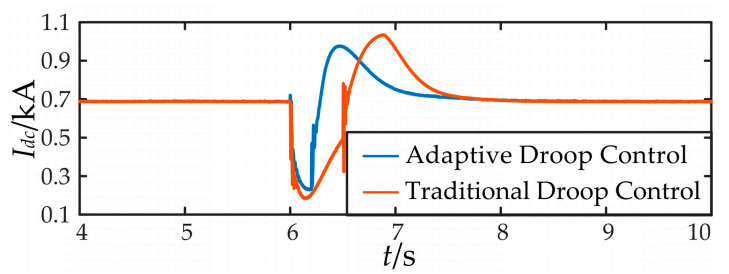

(c)

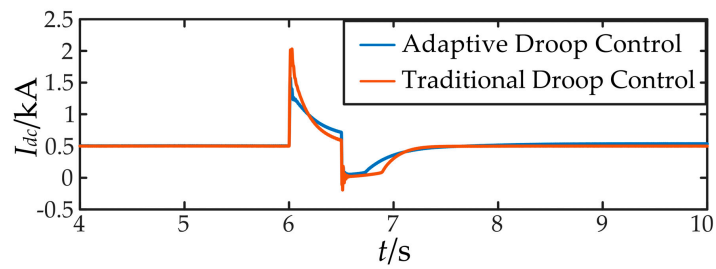

(b)

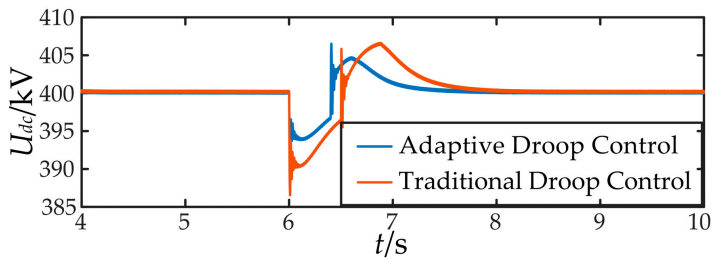

(d)

Figure 16. Simulation waveforms of the three-phase short circuit fault in the AC grid on the LCC 3 side: (a) Active power of VSC1 and VSC2; (b) DC current of LCC3; (c) DC current of LCC4; (d) DC voltage.

Figure16 shows that when the three phase short circuit occurs in the AC network on the LCC 3 side at $6 \mathrm{~s}$, the DC voltage and DC current of each converter station can restore to the initial value after a short period of fluctuation under the two control strategies. Compared with the traditional droop control, the fluctuations of the DC current and DC voltage of the converter stations with the adaptive droop control strategy are smaller. The adaptive droop control strategy has good fault recovery performance and improves the stability of the DC transmission system.

\subsubsection{AC Grid Fault at the Sending End}

In the initial state, the active power instruction values of VSC1 and VSC2 are $300 \mathrm{MW}$ and $200 \mathrm{MW}$, respectively, and the DC current reference values of LCC 3 and LCC4 are $0.5 \mathrm{kA}$ and $0.69 \mathrm{kA}$, respectively. At $6 \mathrm{~s}$, a three phase short circuit fault occurs in the AC grid on the VSC1 side, and the fault lasts $500 \mathrm{~ms}$. The simulation results under traditional DC voltage droop control and DC voltage adaptive droop control are shown in Figure 17.

As shown in Figure 17, under the two control strategies, the DC voltage and DC current of each converter station can restore to the initial value after a short period of fluctuation when the three phase short circuit fault occurs in the AC grid on the VSC1 side. While, the fluctuations of the DC voltage and DC current of the converter stations with adaptive droop control are smaller. That is to say, the adaptive droop control strategy has good fault recovery performance and improves the stability of the DC transmission system. 


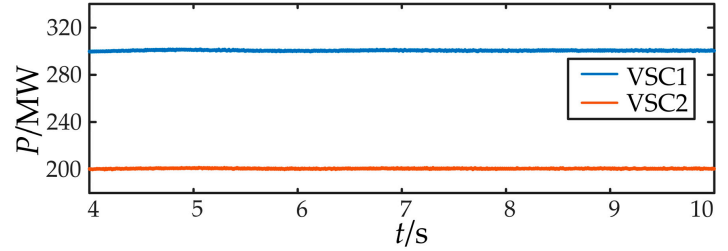

(a)

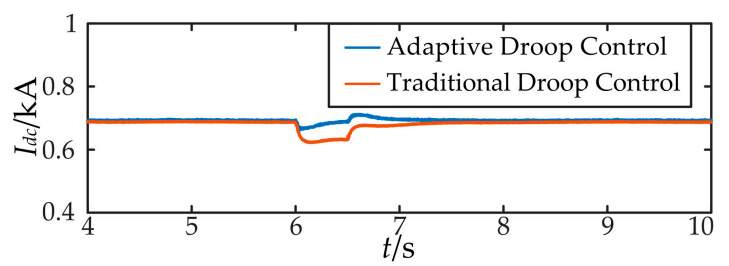

(c)

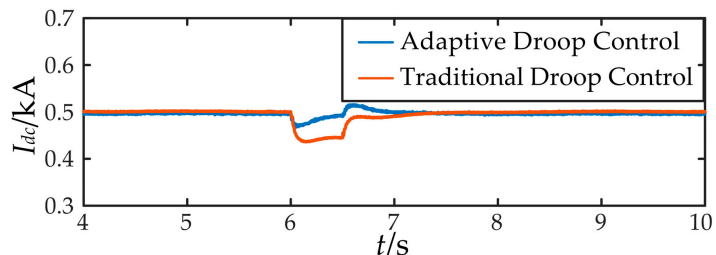

(b)

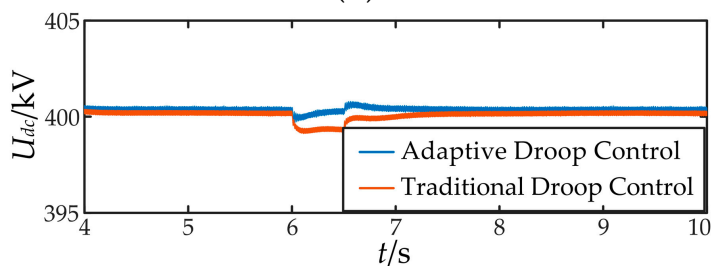

(d)

Figure 17. Simulation waveforms of a three-phase short circuit fault in the AC grid on the VSC1 side: (a) Active power of VSC1 and VSC2; (b) DC current of LCC3; (c) DC current of LCC4; (d) DC voltage.

\subsection{Comparison of Different Adaptive Droop Control}

To verify the effectiveness of the proposed control strategy further, the simulations of the four-terminal hybrid HVDC system with the adaptive droop control based on DC voltage deviation and the adaptive droop control based on the DC voltage deviation coefficient and power distribution coefficient are conducted. It is compared with the simulations of adaptive droop control proposed in this paper.

\subsubsection{Steady-State Simulation Comparison}

In the initial state, the active power instruction values of VSC1 and VSC2 are $250 \mathrm{MW}$ and $400 \mathrm{MW}$, respectively; the DC current reference values of LCC3 and LCC4 are $0.52 \mathrm{kA}$ and $1.0 \mathrm{kA}$, respectively. At $5 \mathrm{~s}$, the active power instruction value of VSC1 rushes to $425 \mathrm{MW}$. At $7 \mathrm{~s}$, the active power instruction value of the VSC1 converter station rushes to $160 \mathrm{MW}$. The simulation results under different adaptive droop control strategies are shown in Figure 18.

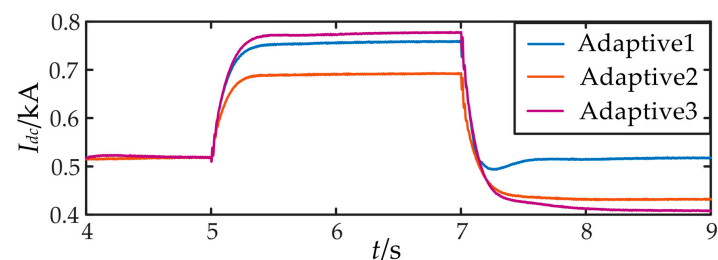

(a)

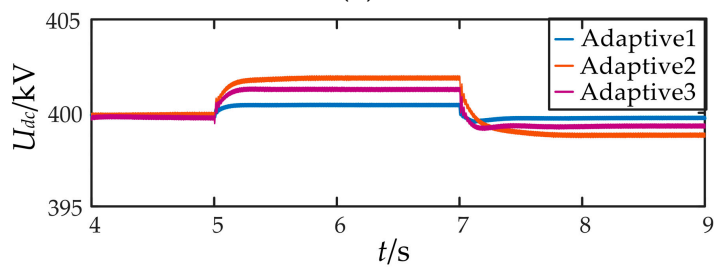

(c)

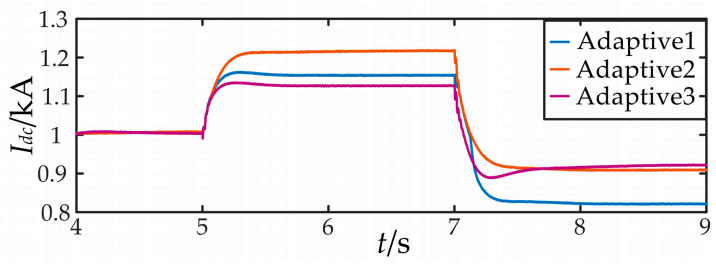

(b)

Figure 18. Simulation waveforms of active power fluctuation: (a) DC current of LCC3; (b) DC current of LCC4; (c) DC voltage. Where Adaptive1, Adaptive2, and Adaptive3 denote the adaptive droop control strategy proposed in this paper, the adaptive droop control based on DC voltage deviation, and the adaptive droop control based on the DC voltage deviation coefficient and power distribution coefficient, respectively. 
As shown in Figure 18, the power margin of the LCC 3 converter station is larger when the active power of VSC1 increases at $5 \mathrm{~s}$. Under the adaptive droop control strategy based on DC voltage deviation, without considering the power margins of the converter stations, the DC current of the LCC4 converter station exceeds the limit. Under the adaptive droop control strategy proposed in this paper, LCC3 undertakes more unbalanced power, which avoids overload of the LCC4 converter station. The power margin of the LCC 4 converter station is larger when the active power of VSC1 decreases at $7 \mathrm{~s}$. Under the adaptive droop control strategy proposed in this paper, LCC4 undertakes more unbalanced power.

From the above analysis, when power flow changes in the Hybrid-MTDC system occur, the converter stations with the adaptive droop control strategy proposed in this paper share the power based on power margins, which improves the power regulation ability of the converter station and prevents the converter stations from overloading. At the same time, the control strategy proposed in this paper can effectively reduce the DC voltage deviation, then the DC voltage quickly stabilizes near the reference value.

\subsubsection{Transient Simulation Comparison}

\section{- $\quad$ LCC3 Being Out of Operation}

In the initial state, the active power instruction values of VSC1 and VSC2 are $300 \mathrm{MW}$ and $200 \mathrm{MW}$, respectively, and the DC current reference values of LCC 3 and LCC4 are $0.5 \mathrm{kA}$ and $0.69 \mathrm{kA}$, respectively. At $5 \mathrm{~s}$, LCC 3 exits due to a failure. The simulation results under different adaptive droop control strategies are shown in Figure 19.

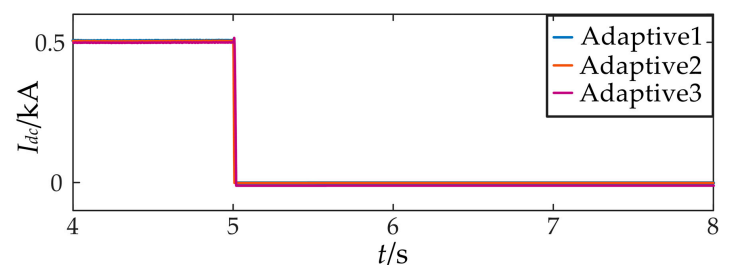

(a)

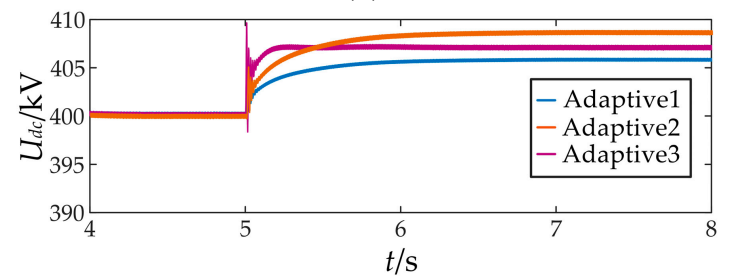

(c)

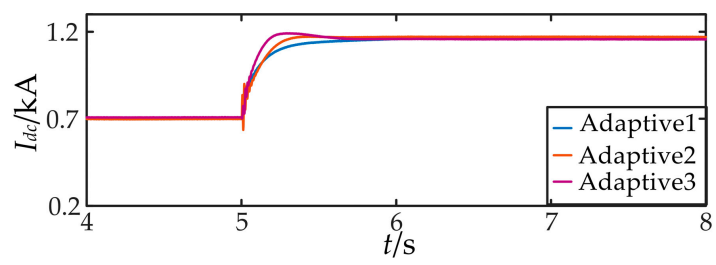

(b)

Figure 19. Simulation waveforms of LCC3 being out of operation: (a) DC current of LCC3; (b) DC current of LCC4; (c) DC voltage. Where Adaptive1, Adaptive2, and Adaptive3 denote the adaptive droop control strategy proposed in this paper, the adaptive droop control based on DC voltage deviation, and the adaptive droop control based on the DC voltage deviation coefficient and power distribution coefficient, respectively.

The simulation results in Figure 19 show that when LCC 3 exits at $5 \mathrm{~s}, \mathrm{LCC} 4$ regulates active power. Under three droop control strategies, the DC current changes of LCC 3 are basically the same. The DC current of LCC4 finally stabilizes at $1.165 \mathrm{kA}$. However, under the adaptive droop control based on the DC voltage deviation coefficient and power distribution coefficient, overshooting of the LCC4 DC current occurs. Furthermore, DC voltage adaptive droop control proposed in this paper minimizes DC voltage deviation while maintaining the stability of the system. 
- AC grid fault at the receiving end

In the initial state, the active power instruction values of VSC1 and VSC2 are $300 \mathrm{MW}$ and $200 \mathrm{MW}$, respectively, and the DC current reference values of LCC 3 and LCC4 are $0.5 \mathrm{kA}$ and $0.69 \mathrm{kA}$, respectively. At $5 \mathrm{~s}$, a three phase short circuit fault occurs in the AC grid on the LCC 3 side, and the fault lasts $500 \mathrm{~ms}$. The simulation results under different adaptive droop control strategies are shown in Figure 20.

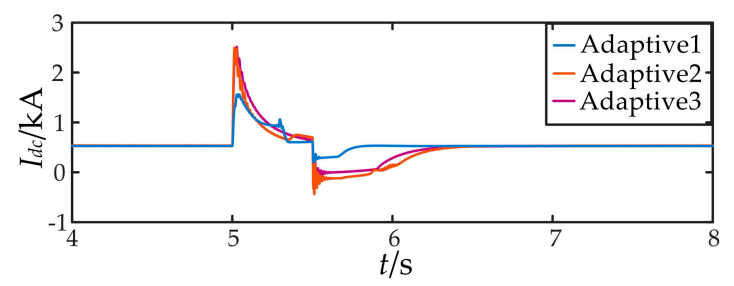

(a)

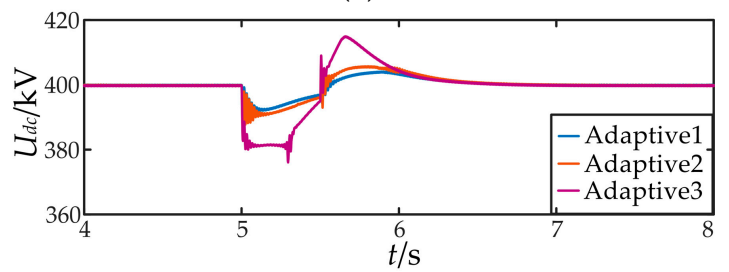

(c)

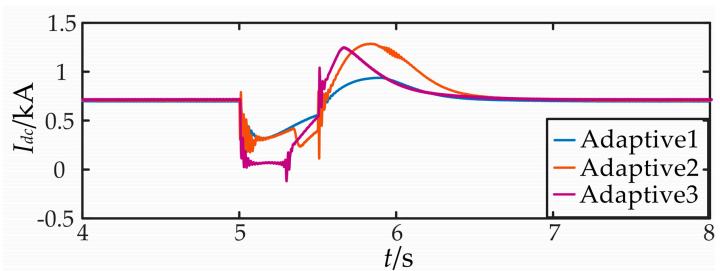

(b)

Figure 20. Simulation waveforms of a three-phase short circuit fault in the AC grid on the LCC3 side: (a) DC current of LCC3; (b) DC current of LCC4; (c) DC voltage. Where Adaptive1, Adaptive2, and Adaptive3 denote the adaptive droop control strategy proposed in this paper, the adaptive droop control based on DC voltage deviation, and the adaptive droop control based on the DC voltage deviation coefficient and power distribution coefficient, respectively.

As shown in Figure 20, under three control strategies, during the fault, both the DC voltage and the DC current fluctuate. After the fault is removed, the DC voltage and DC current return to the initial state after a period of fluctuations. While, the fluctuations of DC voltage and DC current of converter stations with adaptive droop control proposed in this paper are the smallest. That is to say, the adaptive droop control strategy proposed in this paper has good fault recovery performance and improves the stability of the DC transmission system.

\section{Conclusion}

In this paper, a DC voltage adaptive droop control strategy based on DC voltage-current characteristics was proposed for the power allocation and the DC voltage control in the Hybrid-MTDC system. The simulation results verified the feasibility and effectiveness of the proposed control strategy. The main conclusions are as follows:

1. The DC voltage adaptive droop control strategy considers the power margin of the converter station according to the actual operating conditions, so that the converter station with the proposed droop control in the Hybrid-MTDC can share power according to its own power regulating ability. As a result, the converter station avoids the overload caused by an insufficient margin.

2. When power flow changes in the Hybrid-MTDC system occur, the DC voltage of the new steady state is closer to the DC voltage of the original steady state; that is to say, the DC voltage deviation decreases.

3. When faults in the AC grid occur, it has good fault recovery performance and improves the stability of the HVDC system. 
4. There is no need for high-speed communications between converter stations, hence the system responds quickly.

Author Contributions: Conceptualization, Y.L. and L.Z.; Funding acquisition, Y.L. and H.L.; Methodology, Y.L., L.Z. and H.L.; Software, Y.L., L.Z. and H.L.; Validation, Y.L., L.Z. and H.L.; Writing-original draft, Y.L. and L.Z.; Writing-review \& editing, Y.L., L.Z. and H.L.

Funding: This research was funded by National Natural Science Foundation of China, grant number 51607069 and the Fundamental Research Funds for the Central Universities, grant number 2016MS88; 2017MS091.

Acknowledgments: An earlier version of this paper was presented at 2018 IEEE International Conference on Information, Communication and Engineering. The authors would like to express their sincere gratitude to IEEE ICICE 2018 committees for recommending it to submit to Energies.

Conflicts of Interest: The authors declare no conflict of interest.

\section{References}

1. Liu, Y.P.; Zhang, L.; Liang, H.P. DC Voltage Adaptive Droop Control Strategy for Hybrid Multi-Terminal HVDC System. In Proceedings of the 2018 IEEE International Conference on Information, Communication and Engineering, Xiamen, China, 28-30 September 2018.

2. Tang, G.F.; Luo, X.; Wei, X.G. Multi-terminal HVDC and DC-grid technology. Proc. CSEE 2013, 33, 8-17.

3. Zhao, W.G. HVDC Transmission Engineering Technology; China Power Press: Beijing, China, 2011; pp. 7-25.

4. Xu, D.G.; Liu, Y.C.; Wu, J. Review on control strategies of multi-terminal direct current transmission system. Trans. China Electrotech. Soc. 2015, 30, 1-12.

5. Zhao, C.G.; Liu, W.G.; Guo, C.Y. Topology of a hybrid HVDC transmission system for wind power grid connection. Automat. Electr. Power Syst. 2013, 37, 146-151.

6. Wang, Y.P.; Zhao, W.Q.; Yang, J.M. Hybrid high-voltage direct current transmission technology and its development analysis. Automat. Electr. Power Syst. 2017, 41, 156-167.

7. Wu, Y.N.; An, T.; Pang, H. Study on hybrid line commutated converter/voltage source converter DC grid test model. Proc. CSEE 2016, 36, 2077-2083.

8. Huang, W.H.; Rao, H.; Huang, Y. A novel refurbishment scheme for reforming the existing LCC-HVDC to hybrid HVDC. Proc. CSEE 2017, 37, 2861-2868.

9. Abdel-Khalik, A.S.; Massoud, A.M.; Elserougi, A.A. Optimum power transmission-based droop control design for multi-terminal HVDC of offshore wind farms. IEEE Trans. Power Syst. 2013, 28, 3401-3409. [CrossRef]

10. Gomis-Bellmunt, O.; Liang, J.; Ekanayake, J. Topologies of multiterminal HVDC-VSC transmission for large offshore wind farms. Electr. Power Syst. Res. 2011, 81, 271-281. [CrossRef]

11. Pinto, R.T.; Bauer, P.; Sílvio, F.R. A novel distributed direct-voltage control strategy for grid integration of offshore wind energy systems through MTDC network. IEEE Trans. Ind. Electron. 2013, 60, 2429-2441. [CrossRef]

12. Prieto-Araujo, E.; Bianchi, F.D.; Junyent-Ferre, A. Methodology for droop control dynamic analysis of multiterminal VSC-HVDC grids for offshore wind farms. IEEE Trans. Power Deliv. 2011, 26, 2476-2485. [CrossRef]

13. Aragües-Peñalba, M.; Egea-Àlvarez, A.; Gomis-Bellmunt, O. Optimum voltage control for loss minimization in HVDC multi-terminal transmission systems for large offshore wind farms. Electr. Power Syst. Res. 2012, 89, 54-63. [CrossRef]

14. Rouzbehi, K.; Miranian, A.; Luna, A. DC voltage control and power sharing in multiterminal DC grids based on optimal DC power flow and voltage-droop strategy. IEEE J. Emerg. Sel. Top. Power Electron. 2014, 2, 1171-1180. [CrossRef]

15. Li, H.F.; Liu, C.R.; Li, G.Y. DC voltage droop-control strategy for VSC-based HVDC grid. Automat. Electr. Power Syst. 2016, 40, 40-46.

16. Yan, F.Y.; Tang, G.F.; He, Z.Y. An improved droop control strategy for MMC-based VSC-MTDC systems. Proc. CSEE 2014, 34, 397-404.

17. Wang, Y.H.; Chen, Y.; Zeng, Q. Improved droop control strategy for VSC-MTDC. High Volt. Eng. 2018, 44, 3190-3196. 
18. Chaudhuri, N.R.; Chaudhuri, B. Adaptive droop control for effective power sharing in multi-terminal DC (MTDC) grids. IEEE Trans. Power Syst. 2013, 28, 21-29. [CrossRef]

19. Abdelwahed, M.A.; El-Saadany, E.F. power sharing control strategy of multi-terminal VSC-HVDC transmission systems utilizing adaptive voltage droop. IEEE Trans. Sustain. Energy 2016, 8, 605-615. [CrossRef]

20. Kirakosyan, A.; El-Saadany, E.F.; El Moursi, M.S. DC voltage regulation and frequency support in pilot voltage droop controlled multi terminal HVDC systems. IEEE Trans. Power Deliv. 2018, 33, 1153-1164. [CrossRef]

21. Chen, D.P.; Chen, P.; Li, M.H. Optimized droop control stratagey for voltage source converter based multi-terminal directcurrent system. Autom. Electr. Power Syst. 2017, 41, 194-199.

22. Wang, Y.Z.; Wen, W.J.; Wang, C.S. Adaptive Voltage droop control of multiterminal VSC-HVDC systems for dc voltage deviation and power sharing. IEEE Trans. Power Deliv. 2018, 1. [CrossRef]

23. Xu, Z. HVDC-Flexible System; China Power Press: Beijing, China, 2013; pp. 72-77.

(C) 2019 by the authors. Licensee MDPI, Basel, Switzerland. This article is an open access article distributed under the terms and conditions of the Creative Commons Attribution (CC BY) license (http:/ / creativecommons.org/licenses/by/4.0/). 